\title{
Delivering Optimal Fuel Economy and Wear Protection through LUBRICANT DESIGN
}

\author{
Dean Clarke, Isabella Goldmints, Jorge Manes, Katherine Richard \& Margareth Carvalho \\ Infineum Brasil Ltda \\ Infineum USA L.P.
}

dean.clarke@infineum.com, isabella.goldmints@infineum.com, jorge.manes@infineum.com, katherine.richard@infineum.com, margareth.carvalho@infineum.com

\begin{abstract}
The global focus on fuel economy is driven by high fuel prices and the desire to reduce pollution from automotive emissions. This is reflected in continued worldwide legislated decreases in fleet average fuel consumption per mile as well as in greenhouse gas emissions per driven mile. In Brazil, the Inovar-Auto program requires automakers to improve their corporate average vehicle efficiency for new light duty vehicles (LDV) by about $12 \%$ from 2012 levels by October 2017 to qualify for significant tax breaks. The target was based on Europe's 2015 target for new LDVs of $130 \mathrm{~g} \mathrm{CO} / \mathrm{km}$, and adapted to Brazil based on regional differences. These ever-tightening requirements pose a significant challenge for original equipment manufacturers (OEMs) and lubricant formulators. The engine lubricant plays a significant role in reduction of frictional losses and thus fuel consumption, as well as in engine protection from wear. Various additive components in the lubricant are designed for friction reduction in different lubrication regimes thus minimizing the overall friction and resulting in optimal fuel economy. In this paper we demonstrate the fuel economy that lubricant additives as well as lubricant viscosity and viscometric profile can provide while maintaining excellent engine protection.
\end{abstract}

\section{INTRODUCTION}

Inovar-Auto legislation in Brazil was developed in line with the national and global focus on emission reduction and need for improved fuel economy. The requirement to improve the corporate average vehicle efficiency for new light duty vehicles (LDV) by about $12 \%$ from 2012 levels by October 2017 to qualify for significant tax breaks, has renewed the focus among original equipment manufacturers (OEMs) on improving fuel economy. While improvements and redesigns of hardware such as optimization of the combustion process or downsizing the engine can lead to significant fuel economy improvements, it is a lengthy as well as expensive process.

The impact of the lubricant on fuel economy has been recognized and studied for many years [1-6]. It is regarded as a cost effective means to make cars and trucks more fuel efficient. There are several approaches in which an engine lubricant can offer fuel economy improvement. As can be seen in the Stribeck curve (Figure 1), which is a plot of friction as it relates to viscosity, speed and load, there are different lubrication regimes in an engine. 


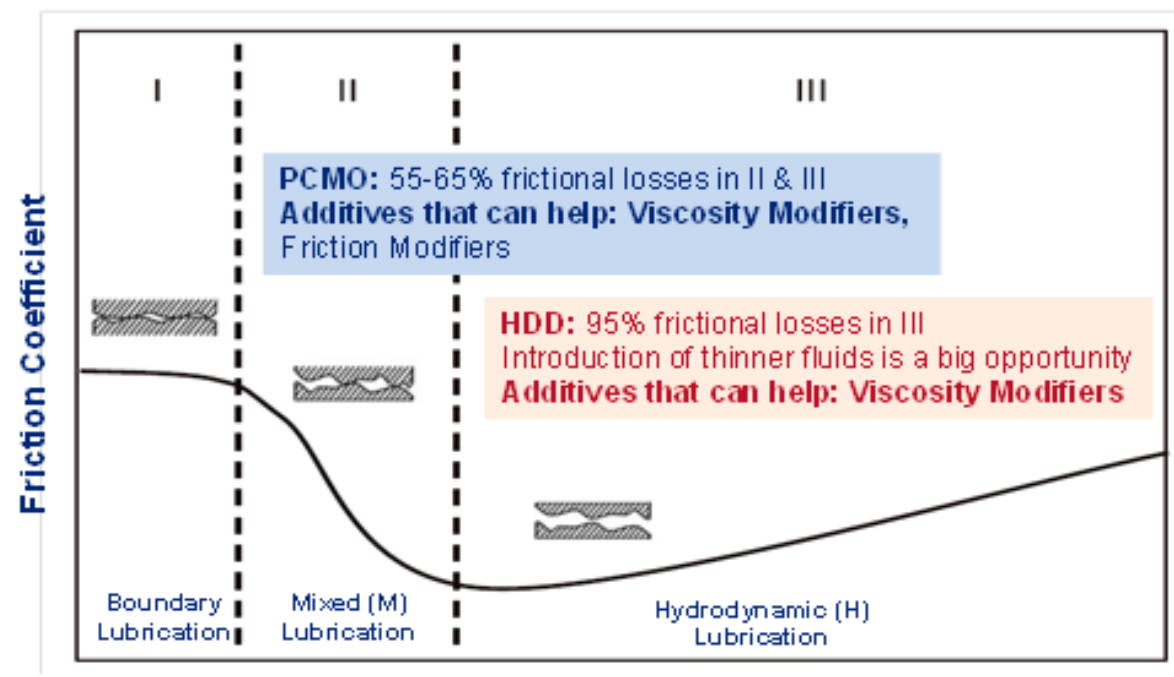

Log (Oil Viscosity x Velocity/ Load)

Figure 1: Stribeck curve.

In the hydrodynamic region, a thick oil film carries the load and separates the surfaces. Hydrodynamic lubrication is found in the engine in the bearings and in the moving pistons.

Elasto-hydrodynamic (EHD) lubrication is found in areas with thin oil films and very high loads, where the lubricant can actually deform the metal surfaces. EHD lubrication is found in valves, piston rings, and roller bearings. The mixed lubrication regime has thin oil films and intermittent contact between the surfaces. Boundary lubrication has no significant oil film, but rather chemical films such as metal oxides, chemically reacted films and physisorbed films. There is repeated metal-metal contact in the boundary regime, leading to high friction. Mixed/boundary lubrication is found in pistons (at low speed or stopped), cams and tappets.

\section{FUEL ECONOMY REVIEW}

\section{Friction Losses in the Engine}

Contributions to friction losses differ between passenger car gasoline and heavy duty diesel engines. Passenger car gasoline engines will see the following contributions to friction losses: piston rings $35-40 \%$, valve train $20-25 \%$, bearings $10-15 \%$, cylinders $10-$ $15 \%$, with $5-20 \%$ attributed to other sources $[7,8]$. However, the exact contribution to friction losses by each engine component will change with engine technology and operating conditions [9]. 55-65\% amount of the friction losses in a passenger car engine are in areas with mixed/boundary lubrication.

Heavy duty diesel engine contributions to friction losses are $\sim 55 \%$ in the piston assembly, $\sim 40 \%$ in the bearings, and $\sim 5 \%$ in the valve train. About $95 \%$ of the friction losses in heavy duty engines are in areas dominated by hydrodynamic lubrication. The relative differences in the friction losses between the two types of engines will require different approaches to fuel economy improvement. 
Extensive modelling has been done to further quantify the specific power losses due to engine components. The relative power losses varied with engine speed, with greater impact of hydrodynamic lubrication regime at higher engine rpm. These studies are outlined in a review article written by Taylor and Coy [10]. This review article also noted that the engine design and driving cycle will also have an impact on the ability of the lubricant to reduce fuel consumption. For example, roller followers have lower inherent friction than slider followers and are therefore less likely to see a large improvement in fuel economy when friction modifiers are added to the formulation. Driving cycles that do not allow the engine to fully warm up will require that viscosity be optimized at the lower end of the operating temperature range, while highway drive cycles would require optimized viscosity at a higher temperature.

\section{Selected OEM views on fuel efficiency}

Deb Morrissett, VP of Regulatory Affairs at Chrysler, gave a speech in March 2008 in which she addressed fuel economy. She noted that the current regulatory change will require an increase in fuel economy of $40 \%$ over today's base line, at a rate of $3.5 \%$ per year. To achieve the required fuel efficiency improvements, she recognized that engine design is not the only component. Powertrain technology and increased use of hybrids and alternative fuels will also play a role [11].

Jim Linden of General Motors gave a presentation regarding fuel economy at the ILMA annual meeting in October 2008. He noted that the primary issue facing the OEMs is fuel economy, driven both by the government and by the consumer. He stated that GM have improved fuel efficiency of cars by $130 \%$ and of trucks by $78 \%$ since 1970 . They have done this by employing several strategies, including equipping smaller engines with turbo chargers and active cylinder management in larger engines. They are also deploying hybrid and electric vehicles. New technology brings new oil requirements, as fuelefficient hardware designs rely on good oil performance throughout the drain interval [12].

\section{Test cycles}

Fuel economy evaluation of the same oil in the same engine depends on the selected drive cycle used to measure fuel consumption [13-17]. There are several drive cycles in use around the world to predict $\mathrm{HC}, \mathrm{CO}$, and NOx emissions and fuel consumption. They differ by length, load, sump temperatures, and combinations of city and highway driving segments. Within Inovar-Auto the average vehicle efficiency is measured in the combined (urban/highway) CAFE cycle which is based on norm ABNT NBR 7024: 2010. The Federal Test Procedure (FTP-75) and New European Driving Cycle (NEDC) are designed to represent typical patterns of light vehicle operation in the USA and Europe respectively [13-17]. While FTP-75 is mostly used by North American OEMs, NEDC is used as guidance by European OEMs when designing and optimizing the engines. Japanese 2005 emission regulation introduced a new, more modern, demanding cycle called JC08 [17], Japan's new standard for 2015 for light vehicles [18]. While the conditions differ 
somewhat between these cycles, the effects of the lubricant on the fuel economy are quite similar.

\section{Impact of Lubricant Composition}

There are several routes to improve fuel economy using the effective lubricant design:

\subsection{Friction modifier technologies}

The purpose of friction modifiers is to reduce boundary friction in the engine and therefore improve fuel economy. There are two main classes of friction modifiers: organic and inorganic, which usually contain molybdenum.

The earliest friction modifiers were based on animal fats, which contain triglycerides. The bulk of commercial friction modifiers for crankcase applications are fatty acid derivatives. However, these friction modifiers have issues; including additive package stability and limited durability in the engine.

Molybdenum-containing friction modifiers are effective by decomposing to form layers of $\mathrm{MoS}_{2}$ on the metal surfaces, which slide by each other with very low friction. The molybdenum is made soluble in the oil by the use of organic complexes, such as carbamates and thiophosphates.

A study was completed on a series of carboxylic acids, in the interest of finding an ideal friction modifier structure. Boundary friction was found to decrease with increasing chain length, increasing temperature and increasing concentration. Higher levels of unsaturation in the chain also led to reduced friction [19].

\subsection{Viscosity Modifier Technologies}

One of the routes to improve fuel economy through the use of lubricant viscosity is to design a lubricant viscometric profile that allows higher HTHS viscosity at $150^{\circ} \mathrm{C}$ to be maintained while reducing the viscosity at lower engine operating temperatures typical of in-service conditions. In general, these oils have higher viscosity index and demonstrate higher fuel economy and use either high VI base oils and/or new classes of Viscosity Index Improvers. The optimal viscometric profile can be made possible by developing the VII, also called VM, to provide the desired viscosity-temperature relationship in the formulated oil. In this case the oil maintains higher HTHS viscosity at $150^{\circ} \mathrm{C}$ which is often correlated to engine wear. When the lubricant is used in current hardware not specifically designed for the very low viscosity oils or when the engine durability is a concern, this approach is considered more attractive to deliver significant fuel economy benefit. 


\subsection{HTHS}

The HTHS viscosity of multigrade engine oils has been previously successfully correlated with the engine friction reduction since the HTHS viscosity is believed to reflect the "effective" viscosity of the oil in the piston ring cylinder area and in connecting rod, main bearing area [20]. Lowering HTHS $150^{\circ} \mathrm{C}$, i.e. moving to lower viscosity grades is a way to improve FE. Historically passenger car engine designs have evolved to accommodate lower viscosity oils, which in turn improve fuel economy by lowering the hydrodynamic friction. However, wear protection and engine durability is still a concern for OEMs with these lower viscosity oils.

\section{SUMMARY}

Fuel economy has been, and continues to be, an area of great interest to the automotive industry as a whole. There are several routes to improve fuel economy through the optimal design of the lubricant: reduction in the overall viscosity, use of friction modifiers, and the use of the specially designed viscosity modifier that delivers fuel economy while providing superior wear performance.

\section{References}

1. Alexandra Dardin, K. H.-M. (n.d.). Influence of PMA VII on the efficiency of lubricants. JASE 20030220/SAE 2003-01-1967.

2. Jingyan Fan, M. M. (n.d.). Reduction of Friction by Functionalised Viscosity Index Improvers, . Tribol Lett (2007) 28:287-298.

3. Klaus Hedrich, M. S. (n.d.). The influence of dispersant PAMA on soot handling: Wear and fuel economy in heavy duty diesel oils. JASE 200030233/SAE 2003-01-1959.

4. Michael Müller, J. F. (n.d.). Design of Functionalized PAMA Viscosity Modifiers to Reduce Friction and Wear in Lubricating Oils . Journal of ASTM International, Vol. 4, No. 10, Paper ID JA1100956.

5. Michael Müller, J. F. (n.d.). Influence of polymethacrylate viscosity index improvers on friction and wear of lubricant formulations. SAE Paper No. 2007-01-1985.

6. Selda Gunsel, M. S. (n.d.). Friction and Wear Reduction by Boundary Film-Forming Viscosity Index Improvers. SAE Paper No. 962037.

7. G. Ryk, Y. Kligerman, I. Etsion, Tribology Transactions, Volume 45, Issue 4, p. 444-449. October 2002.

8. Ian Taylor, "Car Lubricants: Fact and Friction", Physics World, February 2002, p.39-43.

9. R.I. Taylor, "Engine Friction Lubricant Sensitivities: A Comparison of Modern Diesel and Gasoline Engines", Tribotest, 7(1), 2000, 37-43.

10. R.I. Taylor \& R.C. Coy, "Improved Fuel Efficiency by Lubricant Design : A Review"

11. http://www.autobloggreen.com/2008/03/13/chrysler-vp-talks-about-fuel-efficiency-at-saeluncheon/

12. SAE World Congress April 2008 
13. TA, K. R. (n.d.). Development for the Federal Urban Driving Cycle, US Environmental Protection Agency. SAE Paper No. 730553, Washington, DC, 1973.

14. Suryanarayana A N Prasad, M. M. (n.d.). Development of Synthetic Drive Cycle for Fuel Economy Prediction. SAE 2012-01-2048.

15. K. P. Bush, D. C. (n.d.). European Test Methods For Fuel Economy Oils. SAE Paper No. 831741.

16. Nobuo Ushioda, Y. O. (n.d.). Addtive formulation technology for fuel economy passenger car motor oil and development of sequence VID screener. JASE 20119302/SAE2011-012111.

17. P.J. Shayler, N. D. (n.d.). Factors Influencing Drive Cycle Emissions and fuel consumption. SAE paper no. 97160.

18. Japan Automobile Manufacturers Association, Inc. Issue No. 2, 2009. (n.d.).

19. Rebecca Castle and Charles Bovington, "The Behaviour of Friction Modifiers under Boundary and Mixed EHD Conditions", World Tribology Congress 2001

20. J.E. Clevenger, D. C. (n.d.). The Effects of Engine Oil Viscoisty and Composition on Fuel Effciency. SAE Paper No. 841389. 